DOI: 10.20472/IAC.2018.043.018

\author{
ANNELIE JORDAAN \\ Vaal University of Technology, South Africa

\section{MEDIA LITERACY WITHIN A COMMUNITY CONTEXT IN SOUTH AFRICA}

\begin{abstract}
:
The role of e-skills within a community context in South Africa have been conceptualised in 2010 in accordance with the country's National e-Skills Plan (NeSPA). From this, the concept of e-literacy (or digital literacy) within a community context in South Africa has been formulated. A concept that has caught the interest of researchers in education and that has the potential to be included as a learning pathway of e-literacy in future, is media literacy. There is however not yet clarity on the definition and role of media literacy within an e-literate community setting in South Africa. The term "media" encapsulates all types of communication channels, including newspapers, magazines, TV, radio, billboards, mail, telephone, fax and the internet. With the rapid advancement of ICTs, digital media is of specific importance. Media can be biased in various ways, in unpredictable and fluctuating degrees, and for various reasons. This leads us to the question: "How can one consume news without walking away either wrong or disenchanted?" Media literacy offers a solution to this question. This paper examines the status of media literacy in developing countries, with the focus on Africa, and explores how media literacy can contribute to making the community-urban, peri-urban and rural-in South Africa more efficient and well-informed about the world around them, so that they can become scrupulous listeners, readers, and watchers of news and other media and subsequently contribute to democracy. A comprehensive literature review has been adopted as method to provide an overview of media literacy within a community context. Some of the findings include: i) To date, developed countries have provided significantly more support, including funding, for media literacy than developing countries; ii) In developing countries, funding is first and foremost allocated to issues that are crucial and pressing before any medium- and long-term plans, and media literacy is not viewed as one of the essential issues; iii) Although the term "media literary" has been in existence since the eighties, developing countries view the term as "relatively new" and have not yet standardised on a clear and inclusive definition of media literacy within a community context; iv) Developed countries are promoting and rolling out media literacy programmes across the globe; $v$ ) Some developing countries, including Mexico and South Africa, are engaged in research and/or training programmes to promote media literacy nationally.
\end{abstract}

\title{
Keywords:
}

E-skills, e-literacy, media literacy, community, rural

JEL Classification: 124, 128, 038 